Research

\title{
Premature rupture of membranes in HIV infected women
}

\author{
Meena Anshul Khatri ${ }^{1}$, Sunetra Anil Inamdar ${ }^{1}$ \\ Sri Lanka Journal of Obstetrics and Gynaecology 2011; 33: 150-153
}

\begin{abstract}
Objective: To evaluate the outcome of human immunodeficiency virus (HIV) infected women whose pregnancies were complicated by premature rupture of membranes.

Methods: Retrospective study conducted from January 2003 to December 2010. All HIV positive pregnant women with premature rupture of membranes (PROM) were reviewed for vertical transmission of HIV.

Results: Of 17040 pregnant women screened for HIV infection, 67 detected HIV positive, giving a prevalence rate of $0.39 \%$. Of $67 \mathrm{HIV}$ infected women 17 pregnancies were complicated by PROM. Nine women received anti-retroviral (ARV) prophylaxis during antepartum period and three cases of vertical transmission were detected $(17.6 \%)$.

Conclusion: Our limited study suggested, antepartum antiretroviral therapy can result in a significant decline of vertical transmission. Therefore expectant management may be offered to those patients who are on ARVs and develop preterm premature rupture of membranes.
\end{abstract}

Key words: HIV, PROM, vertical transmission, ARV prophylaxis

\section{Introduction}

Premature rupture of membranes occurs in approximately $3 \%$ of all pregnancies accounting for nearly $1 / 3$ of all preterm birth. Moreover, preterm premature rupture of membranes (PPROM) is a contributor to perinatal morbidity and mortality. Management of women with HIV infection who develops preterm premature rupture of membranes

\footnotetext{
${ }^{1}$ Department of Obstetrics and Gynecology, Jawaharlal Nehru Medical College, Datta Meghe Institute of Medical Sciences University, Sawangi, Wardha, India.

Correspondence: Meena Anshul Khatri

E-mail: meenakhatri619@yahoo.com
}

(PPROM) poses an obstetric dilemma ${ }^{1}$. Premature rupture of membranes is a major risk factor for vertical transmission of HIV. In 1995, Minkoff et al described a significant increase in vertical transmission rate if the duration of rupture of membranes was greater than 4 hours in patients with low $\mathrm{CD}_{4}$ level$^{2}$.

\section{Objective}

This study was done to evaluate the perinatal outcome of human immunodeficiency virus (HIV) infected women whose pregnancies were complicated by premature rupture of membranes and to determine the effect of treatment with prophylactic antiretroviral drugs on vertical transmission of the disease.

\section{Methods}

Present study is a retrospective study conducted at Datta Meghe Institute of Medical Sciences University, Wardha, India from Jan. 2003 to Dec. 2010 (over a period of 8 years).

All HIV infected women whose pregnancies are complicated by premature rupture of membranes were reviewed.

Data was extracted with respect to maternal demography (age, parity, year of HIV diagnosis), prenatal care (number of visits, gestational age at initiation of $\mathrm{ART}$, most recent viral load and $\mathrm{CD}_{4}$ count, antiviral therapy), mode of delivery, and perinatal morbidity, mortality and vertical transmission was analyzed.

\section{Results}

Of 17040 pregnant women screened for HIV infection, 67 detected HIV positive giving a prevalence rate of $0.39 \%$. Of the $67 \mathrm{HIV}$ infected women 17 pregnancies were complicated by premature rupture of membranes.

Most of the women visited antenatal clinic in their first or early midtrimester. Paritywise 11 women were primigravidae and six multigravidae. Except for three women diagnosis of HIV infection was confirmed during pregnancy. 
All the women who attended antenatal clinic regularly were screened for viral load and $\mathrm{CD}_{4}$ count and initiated on highly active antiviral therapy (HAART) in early midtrimester. Five patients (patient $6,10,13,14$ and 16) failed to receive antiretroviral therapy (ARVs) due to poor follow up in prenatal clinic, three patients received AZT monotherapy.

Incidence of PROM was $25.37 \%$. Of 17 cases with PROM, 9 patients received antepartum HAART and continued at the time of PROM and remaining 8 cases received single dose of Nevirapine and intravenous Zidovudine during labour.

All the patients received prophylactic antibiotics. Antenatal steroids were given to the patients presented with PPROM before 32 weeks of gestation.

Maximum latency period from PROM to delivery was $72 \mathrm{hrs}$. Three patients delivered vaginally and rest of the patients delivered by cesarean section. Women who failed to receive antepartum antiretroviral therapy (ARVs) were administered intravenous Zidovudine and Nevirapine during labor and the newborns were given syrup Nevirapine or Zidovudine as recommended.

All women were counseled for artificial formula for infant feeding in order to prevent perinatal transmission of HIV. Three cases of vertical transmission were detected $17.6 \%$ (3 of 17 patients).

However none of the 9 patients who received prenatal HAART had vertical transmission. All the three cases of vertical transmission $37.5 \%$ (3 of 8) were from those patients who did not receive HAART. These results occurred irrespective of duration of rupture of membranes, gestational age, maternal viral load and $\mathrm{CD}_{4}$ count.

Table 1. Patients characteristics ${ }^{1}$

\begin{tabular}{|c|c|c|c|c|c|c|c|}
\hline Patient & Age & Parity & $\begin{array}{l}\text { HIV diagnosis } \\
\text { in Pregnancy }\end{array}$ & $\begin{array}{l}\text { Duration of } \\
\text { HIV infection } \\
\text { (in years) }\end{array}$ & $\begin{array}{l}\text { Viral load } \\
\text { (copies/ml) }\end{array}$ & $\begin{array}{l}C D_{4} \text { count } \\
\left(a b s / m^{3}\right)\end{array}$ & $\begin{array}{l}\text { Antepartum } \\
\text { therapy }\end{array}$ \\
\hline 1 & 22 & Primi & Yes & 0 & NA & NA & Combivir \\
\hline 2 & 26 & Primi & Yes & 0 & NA & NA & AZT \\
\hline 3 & 24 & Primi & Yes & 0 & $<50$ & 884 & Combivir \\
\hline 4 & 19 & Primi & Yes & 0 & NA & NA & AZT \\
\hline 5 & 19 & Primi & Yes & 0 & 170 & 544 & Combivir, Nevirapine \\
\hline 6 & 22 & Primi & Yes & 0 & NA & NA & None \\
\hline 7 & 28 & $\mathrm{G}_{2} \mathrm{P}_{1} \mathrm{~L}_{1}$ & No & 1 & 198 & 640 & Combivir, Nevirapine \\
\hline 8 & 26 & $\mathrm{G}_{2} \mathrm{~A}_{1}$ & Yes & 0 & $<50$ & 960 & $\begin{array}{l}\text { Nevirapine, Lamivudine, } \\
\text { Stavudine }\end{array}$ \\
\hline 9 & 21 & $\mathrm{G}_{2} \mathrm{P}_{1} \mathrm{~L}_{1}$ & No & 2 & $<50$ & 560 & Combivir, Nevirapine \\
\hline 10 & 19 & Primi & Yes & 0 & NA & NA & None \\
\hline 11 & 30 & $\mathrm{G}_{3} \mathrm{P}_{1} \mathrm{~A}_{1}$ & No & 2 & 178 & 612 & Combivir, Nevirapine \\
\hline 12 & 22 & Primi & Yes & 0 & $<50$ & 880 & Combivir, Nevirapine \\
\hline 13 & 22 & $\mathrm{G}_{2} \mathrm{~A}_{1}$ & Yes & 0 & NA & NA & None \\
\hline 14 & 28 & $\mathrm{G}_{2} \mathrm{P}_{1} \mathrm{~L}_{1}$ & Yes & 0 & NA & NA & None \\
\hline 15 & 19 & Primi & Yes & 0 & 58 & 776 & AZT \\
\hline 16 & 20 & Primi & Yes & 0 & $<50$ & 854 & None \\
\hline 17 & 24 & Primi & Yes & 0 & 271 & 588 & Combivir, Nevirapine \\
\hline
\end{tabular}

NA - data Not Available, AZT - Zidovudine 
Table 2. Premature rupture of membranes and delivery characteristics ${ }^{1}$

\begin{tabular}{ccccccc}
\hline Patient & $\begin{array}{c}\text { Gestational age } \\
\text { at PROM (in weeks) }\end{array}$ & Antibiotic & $\begin{array}{c}\text { Antenatal } \\
\text { steroids }\end{array}$ & $\begin{array}{c}\text { Interval to } \\
\text { delivery }\end{array}$ & $\begin{array}{c}\text { Modeof } \\
\text { delivery }\end{array}$ & $\begin{array}{c}\text { Vertical } \\
\text { transmission }\end{array}$ \\
\hline 1 & 33 & Yes & Yes & 1 & CS & No \\
2 & 31.5 & Yes & Yes & 1 & CS & No \\
3 & 29.5 & Yes & Yes & 1 & CS & No \\
4 & 36 & Yes & No & 1 & VD & No \\
5 & 32 & Yes & Yes & 1 & VD & No \\
6 & 28.5 & Yes & Yes & 2 & CS & No \\
7 & 37 & yes & No & 1 & CS & No \\
8 & 38 & yes & No & 1 & CS & No \\
9 & 37.2 & Yes & Yes & 1 & CS & No \\
10 & 32.2 & Yes & No & 1 & CS & yes \\
11 & 37 & Yes & No & 1 & VD & No \\
12 & 32.5 & Yes & No & 3 & CS & No \\
13 & 29.6 & Yes & Yes & 3 & CS & No \\
14 & 33 & Yes & No & 1 & CS & yes \\
15 & 32 & yes & No & 3 & CS & No \\
16 & 30.5 & yes & No & 1 & CS & Yes \\
17 & 29.2 & Yes & Yes & 2 & CS & No \\
\hline
\end{tabular}

CS - Caesarean Section, VD - Vaginal Delivery

\section{Discussion}

In pregnancies complicated by maternal HIV infection, duration of rupture of membranes $>4$ hours in term pregnancies appear to increase the risk of intrapartum vertical transmission ${ }^{4,5}$. In a study assessing ${ }^{6}$ prolong rupture of membranes in term $(>37$ weeks) relative to preterm ( $<37$ weeks) the author found 3.8-fold RR (95\% CI 1.9,7.8) increase in intrapartum HIV transmission in preterm compared to term infants whose membranes had been ruptured $>4$ hours. However transmission risk was not stratified by the use of antiretroviral therapy, gestational age, nor mode of delivery ${ }^{6}$ however in our study duration of membrane rupture was not a risk factor for vertical transmission. Interestingly monotherapy or lack of antiretroviral therapy were independently associated with neonatal infection and our case series suggests that those HIV infected mothers who received antepartum HAART and delivered by cesarean section vertical transmission has not occurred in the preterm infants (gestational age $<32$ weeks patient- 2, 3, 6, 13 and 17). This shows that preterm infants are not at increased risk of acquiring infection at the time of delivery and definitely there is direct relationship between combination of antiretroviral therapy and mode of delivery to reduce the rate of vertical transmission.

Our limited study suggests that expectant management may be offered to those patients who are on antepartum ARVs and developed preterm premature rupture of membranes.

\section{References}

1. Aagaard-Tillery KM, Lin MG, Lupo V, Buchbinder A, Ramsey PS. Preterm premature rupture of membranes in HIV infected women: a novel case series. Infect Dis Obstet Gynecol 2006: 53234. Published online 2006 April 20.

2. Alvarez JR, Apuzzio JJ. Controversies in the management of preterm premature rupture of membranes. Progress In Obstetrics and Gynecology 18: 203-22. 
3. Prevention Of Mother To Child Transmission of HIV: Our Experience In South India. Karthekeyani V, Alexander G, Solomon E, Rao S, Rao PS, Sunder S. The Journal of Obstetrics and Gynecology of India 2011; 61: 62-6.

4. Landesman SH, Kalish LA, Burns DN, et al. Obstetrical factors and the transmission of human immunodeficiency virus type 1 from mother to child. The New England Journal of Medicine 1996; 334(25): 1617-23.

5. The International Perinatal HIV group. Duration of ruptured membranes and vertical transmission of HIV-1: a metaanalysis from 15 prospective cohort studies. AIDS. 2001; 15(3): 357-68.

6. Kuhn L, Steketee RW, Weedon J, et al. Distinct risk factors for intrauterine and intrapartum human immunodeficiency virus transmission and consequences for disease progression in infected children. The Journal of Infectious Diseases 1999; 179(1): 52-8. 